\title{
GLOBAL RELATIONS BETWEEN SEISMIC FAULT PARAMETERS AND MOMENT MAGNITUDE OF EARTHQUAKES
}

\author{
Papazachos B. C., Scordilis E. M., Panagiotopoulos D. G., Papazachos C. B. and \\ Karakaisis G. F. \\ Geophysical Laboratory, School of Geology, Aristotle University of Thessaloniki, PO Box 352-1, \\ 54124,Thessaloniki,manolis@geo.auth.gr, panagiot@geo.auth.gr
}

\begin{abstract}
The most reliable of the globally available relative data have been used to derive empirical formulas which relate the subsurface fault length, L, the fault area, $S$, and fault width, w, with the moment magnitude, $M$. Separate such formulas have been derived for earthquakes generated by strike-slip faulting, by dip-slip faulting in continental regions and by dip-slip faulting in lithospheric subduction regions. The formula which relates the fault area with the magnitude is combined with the definition formulas of seismic moment and moment magnitude to derive also relations between the fault slip, $u$, and the moment magnitude for each of the three seismotectonic regimes. For a certain magnitude, the fault length is larger for strike-slip faults than for dip-slip faults, while the fault width is small for strike-slip faults, larger for dip-slip faults in continental regions and much larger for dip-slip faults in regions of lithospheric subduction. For a certain magnitude, fault slip is about the same for strike-slip faults and dip-slip faults in continental regions and smaller for dip-slip faults in regions of lithospheric subduction.
\end{abstract}

\section{INTRODUCTION}

Relation between fault parameters (fault length, fault area, fault slip) and the magnitude of the corresponding earthquake are of importance for practical purposes, because these relations can be used to estimate the magnitude of an earthquake when such parameters are known (from geological observations, space distribution of aftershocks, etc.). Such empirical relations are also of importance for theoretical reasons because they can be used to test the validity of models on the mechanics of seismic rupture. For this reason several such relations have been already proposed (Utsu \& Seki 1954, Tocher 1958, Kanamori \& Anderson 1975, Bonilla et al. 1984, Wesnousky 1986, Ambraseys 1988, Wells \& Coppersmith 1994, Wang \& Ou 1998, Smith \& Stock 2000, Papazachos \& Papazachou 2003). There are, however, important differences between such published relations, due mainly to uncertainties of the data used. A result of such uncertainties is the proposal of two different models for scaling of fault slip in large earthquakes (Romanowicz 1994, Scholz 1994a,b).

One of the most important results of the up to now relative work is the publication of observations which concern the fault length, $L$, the fault area, $S$, (or the fault width, w), of a very large number of earthquakes (for about 500 earthquakes with moment magnitudes between 5.0 and 9.6). This large set of available observations gives now the possibility to apply strict enough and consistent criteria in order to obtain a sample of data which is of a satisfactory size (satisfactory number of fault cases), homogeneous (fault parameters estimated by the same method, earthquake magnitudes in the same scale), accurate enough (accurate fault parameters, magnitudes) and, therefore, proper for deriving reliable scaling relations. Thus, the goal of the present paper is to apply such criteria, which are described in the next section, in order to derive relations between, $L$ and $M, S$ and $M, w$ and $M$ for strike-slip faults, for dip-slip faults in continental regions and for dip-slip faults in regions of lithospheric subduction. Relations between fault slip, $u$, and $M$ are also derived for these three categories of seismotectonic regimes but these relations are partly based on observations and partly on the relations by which the seismic moment and moment magnitude are derived. 


\section{DATA AND PROCEDURE FOLLOWED}

Available information on fault parameters is mainly coming from field observations, from space distribution of aftershocks and from modeling of faults by using seismic, geodetic and tsunami data. Field observations, however, do not concern the parameters of the real (subsurface) fault but parameters of the surface expression of the fault (length and slip of the surface trace of the fault). Furthermore, such field observations do not give much information on the width (or area) of the real fault. Since we are interesting in relations between the parameters of the real (subsurface) faults and the moment magnitude of the corresponding earthquake, data mainly coming from space distribution of aftershocks and some data coming from fault modeling are used in the present study.

Such data have been produced by many researchers all over the world and have been summarized and published recently in certain scientific papers (Wells \& Coppersmith 1994, Pegler \& Das 1995, Stock \& Smith 2000, Fujii \& Matsu'ura 2000, Henry \& Das 2001, Kagan 2002, Papazachos \& Papazachou 2003). The values of the fault length, $L$, and of the fault areas, $S$, which are sited in these papers and for which reliable moment magnitudes, $M$, are available, are used in the present work. Since there are no direct observations on the mean displacement, $u$, of the real fault, the relation between, $\mathrm{u}$ and $\mathrm{M}$, has been derived by combining the derived relation between $\mathrm{S}$ and $\mathrm{M}$, the definition relation of the seismic moment,

$$
M_{0}=\mu S u
$$

(Aki 1966) and the definition relation of the moment magnitude

$$
\log M_{0}=1.5 M+16.1
$$

where $M_{0}$ is in dyn.cm (Hanks \& Kanamori 1979).

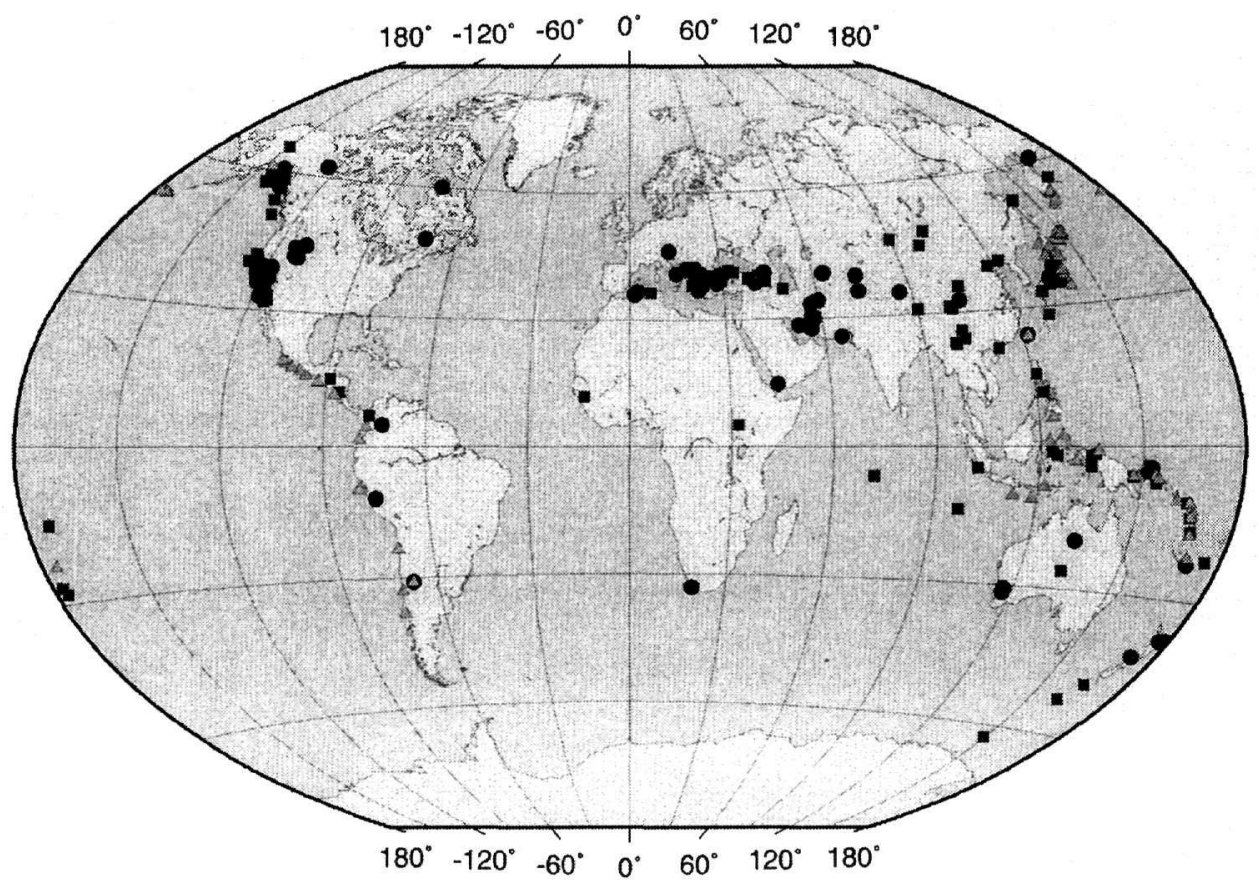

Figure 1. Index map of the epicenters of earthquakes for which data are used in the present study. Rectangles, circles and triangles show earthquakes with strike-slip faulting, dip-slip faulting in continental regions and dipslip faulting in regions of lithospheric subduction, respectively. 
Faults corresponding to strong earthquakes $(M \geq 5.8)$ are considered in the present paper because for such faults the observations $(M, L, S)$ are more accurate and these faults are of more interest from practical point of view. Such relative large faults can be considered as orthogonal and the fault area, $S$, is the product of the fault length, $L$, which can take relatively large values, and the width, $w$, which cannot take large values due to the relatively small thickness of the seismogenic layer. The saturation value of $w$ depends on the seismotectonic regime. This is expected to be: small for strike-slip faults which break almost vertically the relatively thin horizontal seismogenic crustal layer, large for dip-slip (normal or thrust) faults, which break obliquely this layer, and largest for dip-slip faults in lithospheric subduction areas. For this reason we investigated separately each one of these three categories of faults.

Based on the above mentioned criteria, we made a catalogue which gives information for 116 strike-slip faults, for 77 dip-slip faults in continental regions and for 72 dip-slip faults in subduction regions. Figure 1 shows the epicenters of these 265 earthquakes, where three symbols are used for the corresponding three categories of seismotectonic regimes.

All earthquake magnitudes used in this paper are reliably determined moment magnitudes, $M$, based on instrumental data and their errors are within a rather narrow window $(\approx \pm 0.2)$. For this reason the logarithms of the fault length, $\log \mathrm{L}$, and of the fault areas, $\log \mathrm{S}$, have been plotted against the magnitudes and the least squares' method has been applied on the five points' moving average to calculate the parameters of the relations.

\section{RESULTS}

Relations between the fault parameters $(L, S, w, u)$ and the moment magnitude of the corresponding magnitude have been derived by the procedure already described, separately for each of the three kinds of seismotectonic regimes.

\subsection{Strike-slip faults}

For 100 of 116 strike-slip faults considered, the fault lengths $L$ (in $\mathrm{km}$ ), are known. The data are fitted (Fig. 2 a) by the relation:

$$
\log L=0.59 M-2.30, \quad \sigma=0.14, \quad 6.0 \leq M \leq 8.0
$$

where $\sigma$ is the standard deviation for the original data. For 54 of 72 strike-slip faults considered the values of the fault areas, $\mathrm{S}$ (in $\mathrm{km}^{2}$ ), are available and are fitted (Fig. 3a) by the relation:

$$
\log S=0.82 \mathrm{M}-2.79, \quad \sigma=0.19, \quad 6.0 \leq \mathrm{M} \leq 8.0
$$

If we assume that faults are orthogonal, from relations $(3,4)$ we receive the following relation between the fault width, $w$ (in $\mathrm{km}$ ), and the moment magnitude:

$$
\log w=0.23 \mathrm{M}-0.49 \quad 6.0 \leq \mathrm{M} \leq 8.0
$$

From relations $(1,2,4)$ we receive the following formula for the mean displacement, $u$ (in $\mathrm{cm}$ ), at the fault:

$$
\operatorname{Logu}=0.68 \mathrm{M}-2.59 \quad 6.0 \leq \mathrm{M} \leq 8.0
$$

\subsection{Dip-slip continental faults}

There are available fault length values for 69 dip-slip (thrust or normal) faults in continental areas. The lengths, $L$ (in $\mathrm{km}$ ), of these faults and the corresponding magnitudes are fitted (Fig. $2 \mathrm{~b}$ ) by the relation:

$$
\log L=0.50 M-1.86, \quad \sigma=0.13, \quad 6.0 \leq M \leq 7.5
$$



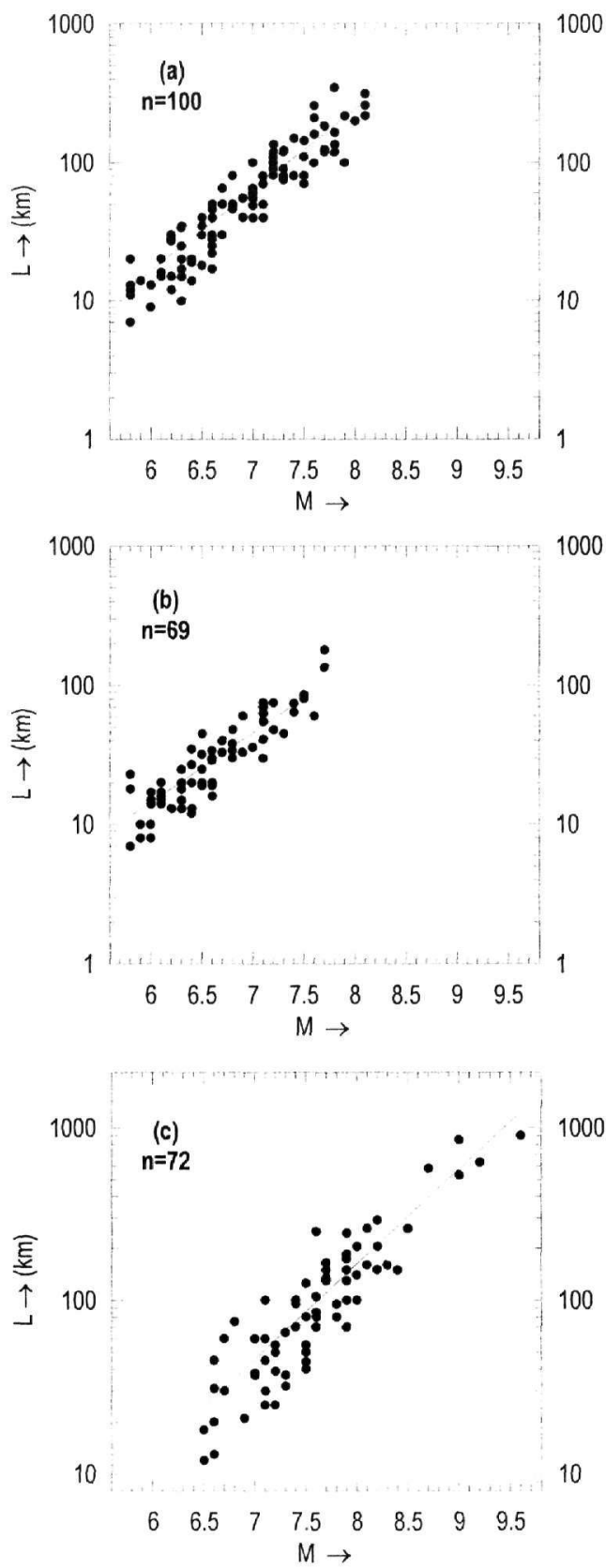

Figure 2. Variation of the logarithm of the observed fault length, $L$ (in $\mathrm{km}$ ), as a function of the moment magnitude, $M$, for: a) strike-slip faults, b) dip-slip faults in continental regions, c) dip-slip faults in regions of lithospheric subduction. Straight lines are least squares' fit to the data.

which is almost identical to a relation derived for the Aegean area (Papazachos \& Papazachou 2003). Figure $3 b$ shows a plot of the logarithm of the area, $S$ (in $\mathrm{km}^{2}$ ), versus the corresponding magnitude for 63 cases of dip-slip faults for which such reliable data are available. These data are fitted by the relation:

$$
\log S=0.78 M-2.56, \quad \sigma=0.21, \quad 6.0 \leq M \leq 7.5
$$



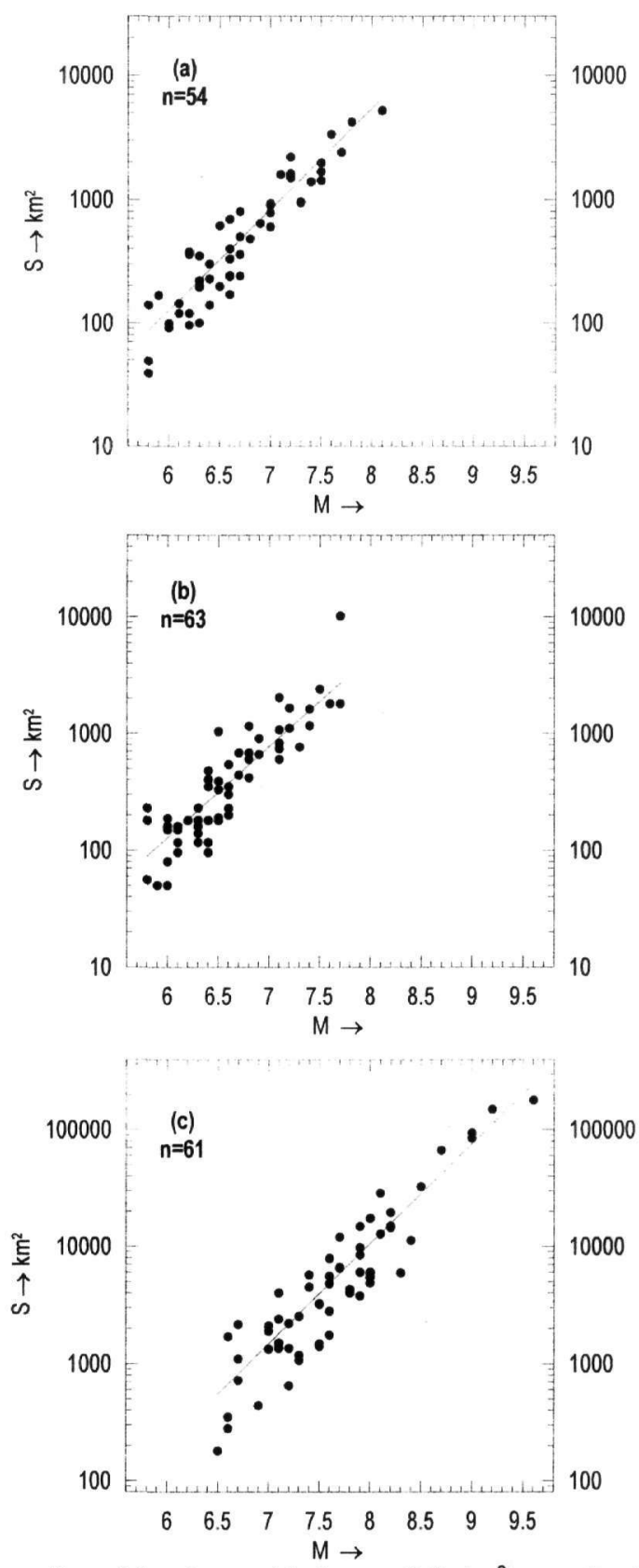

Figure 3. Variation of the logarithm of the observed fault area, $S$ (in $\mathrm{km}^{2}$ ), as a function of moment magnitude, $M$, for: a) strike-slip faults, b) dip-slip faults in continental regions, c) dip-slip faults in regions of lithospheric subduction. Straight lines are least squares' fits to the data.

Assuming that these dip-slip continental faults, are rectangular, we receive the following formula for the fault width, $w$ (in $\mathrm{km}$ ), from relations $(7,8)$ :

$$
\log w=0.28 M-0.70, \quad 6.0 \leq M \leq 7.5
$$


The relations $(1,2,8)$ give the formula :

$$
\log u=0.72 M-2.82, \quad 6.0 \leq M \leq 7.5
$$

where, $u$ (in $\mathrm{cm}$ ), is the mean displacement at a dip-slip continental fault.

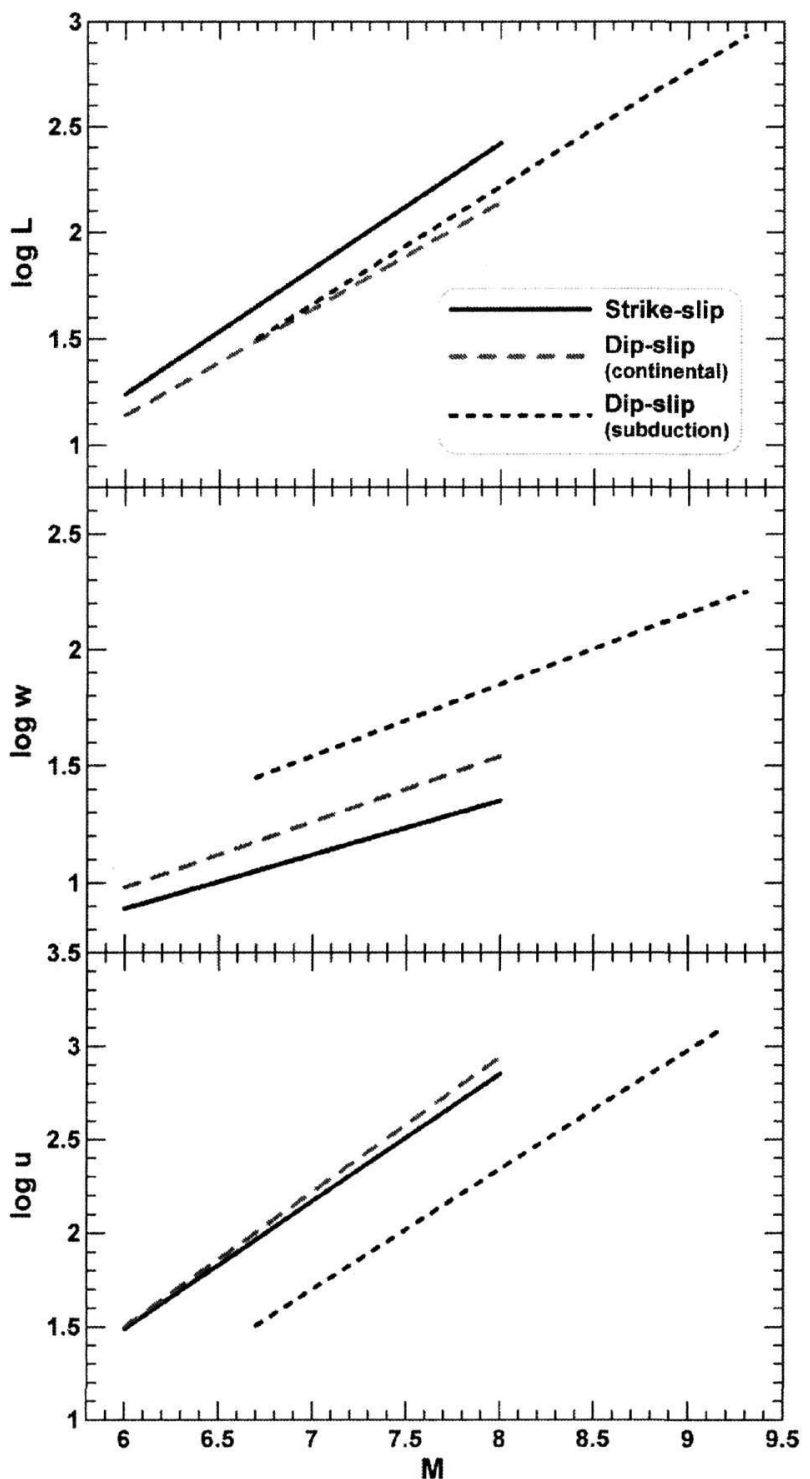

Figure 4. Variation of the logarithm of the fault length, $L$, of the fault width, $w$, and of the fault slip, $u$, as a function of the moment magnitude, M, for strike-slip, dip-slip continental and dip-slip subduction earthquakes.

\subsection{Dip-slip faults in subduction regions}

Figure $2 c$ shows the logarithm of the fault length, $L$ (in $\mathrm{km}$ ), for 72 faults in lithospheric subduction areas for which such reliable data are available. The following relation fits the data:

$$
\log L=0.55 M-2.19, \quad \sigma=0.18, \quad 6.7 \leq M \leq 9.3
$$


The plot of the logarithm of the area, $\mathrm{S}$ (in $\mathrm{km}^{2}$ ), of 61 dip-slip faults in subduction zones for which the values of such areas are available, as a function of the magnitude, is given in figure $3 \mathrm{c}$. These data are fitted by the relation:

$$
\log S=0.86 \mathrm{M}-2.82, \quad \sigma=0.25, \quad 6.7 \leq \mathrm{M} \leq 9.2
$$

From relations $(11,12)$ we find that the fault width, $w$ (in $\mathrm{cm}$ ), of dip-slip faults in lithospheric subduction areas is given by the relation:

$$
\log w=0.31 \mathrm{M}-0.63, \quad 6.7 \leq \mathrm{M} \leq 9.2
$$

Relations $(1,2,12)$ give the following relation between the mean displacement, $u$ (in $\mathrm{cm}$ ), at the dipslip faults in subduction areas and the magnitude of the corresponding earthquake:

$$
\log u=0.64 M-2.78, \quad 6.7 \leq M \leq 9.2
$$

\section{CONCLUSIONS}

In order to identify differences between the fault parameters $(L, w, u)$ in the three different seismotectonic regimes, each of these parameters has been plotted in the same figure 4. Figure 4a shows the plot of the subsurface fault length, $L$ (in $\mathrm{km}$ ), against the moment magnitude, $M$, for the three seismotectonic regimes. It is observed that the length of the strike-slip faults is larger than the fault length of the dip-slip faults for given magnitude. Thus, for $M=7.0$, the fault length is $68 \mathrm{~km}$ for a strike-slip fault, $44 \mathrm{~km}$ for a dip-slip fault in a continental region and $46 \mathrm{~km}$ for a dip-slip fault in a region of lithospheric subduction.

Figure $4 \mathrm{~b}$ shows the plot of the fault width, $w($ in $\mathrm{km}$ ), versus the moment magnitude. The widths of the strike-slip faults are relatively small, the widths of the dip-slip faults in continental regions are larger and the widths of the dip-slip faults in regions of lithospheric subduction are much larger. Thus, for $M=7.0$, the fault width is $13 \mathrm{~km}$ for a strike-slip fault, $18 \mathrm{~km}$ for a dip-slip fault in a continental region and $35 \mathrm{~km}$ for a dip-slip fault in a region of lithospheric subduction.

Figure $4 \mathrm{c}$ shows a plot of the mean fault displacement. The fault displacement is about the same for strike-slip faults and for dip-slip faults in continental regions and much smaller for dip-slip faults in regions of lithospheric subduction, for a given magnitude. Thus, for $M=7.0$, the fault displacement is $148 \mathrm{~cm}$ for strike-slip faults, $166 \mathrm{~cm}$ for dip-slip faults in continental regions and $50 \mathrm{~cm}$ for dip-slip faults in regions of lithospheric subduction.

It must be pointed out that the results of the present work concern properties of real (subsurface) seismic faults. It will be of interest to examine properties of the surface expressions of faults (length of surface faults trace, surface fault displacement), but this is our next relative goal.

\section{REFERENCES}

Aki K. 1966. Generation and propagation of G-waves from the Niigata earthquake of June 16,1964. 2. Estimation of earthquake movement, released energy and stress-strain drop from $\mathrm{G}$ spectrum. Bull. Earthq. Res. Inst., 44, 23-88.

Ambraseys N.N. 1988. Magnitude - fault length relationships for earthquakes in the Middle East, In: Historical Seismograms and Earthquakes of the World, Lee, W.H., Meyers, H. \& Shimazaki, K. eds, Acad. Press Inc., 309-310.

Bonilla M., Mark R. \& Lienkaemper J. 1984. Statistical relations among earthquake magnitude, surface length and surface fault displacements. Bull. Seism. Soc. Am., 74, 2379-2411.

Fujii Y. \& Matsu'ura M. 2000. Regional difference in scaling laws for large earthquakes and its tectonic implication. Pure Appl. Geophys., 157, 2283-2302.

Hanks T.C. \& Kanamori H. 1979. A moment magnitude scale. J. Geophys. Res., 84, 2348-2350.

Henry C. \& Das S. 2001. Aftershocks zones of large shallow earthquakes: fault dimensions, aftershock area expansion and scaling relations. Geophys. J. Int., 147, 272-293.

Kagan Y.Y. 2002. Aftershock zone scaling. Bull. Seism. Soc. Am., 92, 641-655. 
Kanamori H. \& Anderson D.C. 1975. Theoretical basis of some empirical relations in seismology. Bull. Seism. Soc. Am., 65, 1073-1096.

Papazachos B.C. \& Papazachou C.B. 2003. The earthquakes of Greece. Ziti Publications, Thessaloniki, 273pp.

Pegler G. \& Das S. 1996. Analysis of the relationship between seismic moment and fault length for large crustal strike-slip earthquakes between 1977-92. Geophys. Res. Letters, 23, 905-908.

Romanowicz B. 1994. Comments on A Reappraisal of Large Earthquake Scaling by C. Scholz. Bull. Seism. Soc. Am., 84, 1675-1676.

Scholz C.H. 1994a. A reappraisal of large earthquake scaling. Bull. Seism. Soc. Am., 84, 215-218.

Scholz C.H. 1994b. Reply on comments on Reappraisal of Large Earthquake Scaling by C. Scholz. Bull. Seism. Soc. Am., 84, 1677-1678.

Smith G.C. \& Stock Ch. 2000. Evidence for different scaling of earthquake source parameters for large earthquakes depending on faulting mechanism, Geophys. J. Int., 143, 157-169.

Stock C. \& Smith E.G.C. 2000. Evidence for different scaling of earthquake source parameters for large earthquakes depending on faulting mechanism. Geophys. J. Int., 143, 157-162.

Tocher D. 1958. Earthquake energy and ground breakage. Bull. Seism. Soc. Am., 48, 147-153.

Utsu T. \& Seki A. 1954. A relation between the area of aftershock region and the energy of mainshock. J. Seism. Soc. Japan, 7, 233-240.

Wang J.H. \& Ou S.S. 1998. On scaling of earthquake faults. Bull. Seism. Soc. Am., 88, 758-766.

Wells D.L. \& Coppersmith K.J. 1994. New empirical relationships among magnitude, rupture length, rupture width, rupture area and surface displacement. Bull. Seism. Soc. Am., 84, 974-1002.

Wesnousky S.G. 1986. Earthquake, quaternary faults and seismic hazard in California. J. Geophys. Res., 91 , $12587-12631$. 